\title{
VASCULAR SURGERY
}

\section{A letter to Major-General Philip Mitchiner}

This is a letter written in response to an article in the first issue of the Annals, which is being republished as a 70th birthday celebration. The original article is printed after this letter and is available online at: http://publishing.rcseng.ac.uk/doi/full/ 10.1308/annrcse00001-0036

\section{Dear Major-General Mitchiner,}

I read with interest the transcript of your lecture on gangrene delivered at the College and published in the Annals of The Royal College of Surgeons of England (issue 1, pages 31-36), and thought you might like know what progress has been made on the topic in the last 70 years. Sadly, we still see gangrene frequently in surgical practice. Indeed, your excellent pathological descriptions are (for the most part) still apt today.

I am sure you would be interested to hear that the predominant aetiologies have changed over the years, with a negligible incidence of ergotism and syphilis, and carbolic gangrene is no longer apparent. A far greater incidence arises from atherosclerosis spurred on by tobacco smoking and diabetes. Far from being the social nicety of your day, the cigarette has become the pariah of modern living, with many campaigning for its abolition. We have added a few more subsets of aetiologies for gangrene to your comprehensive list including vasculitis, septicaemia, compartment syndrome and the infusion of inotropic drugs.

You will, however, be heartened to learn that some means of prevention have been developed. Best medical therapy has been found to reduce the progression of atherosclerotic arterial stenosis, now termed peripheral arterial disease. This constitutes smoking cessation, antiplatelet and statin therapy (a drug that lowers cholesterol), supervised exercise and risk factor management. An association between peripheral arterial disease, ischaemic heart disease and stroke is now well documented, and the above measures are recommended as much to reduce the incidence of these life threatening conditions.

Imaging of the vasculature has also moved on from routine, invasive, diagnostic intra-arterial angiography. First, ultrasonography has been combined with the Doppler effect to give us real time imaging of blood flow (so-called duplex imaging). Furthermore, computers are now able to reconstruct angiographic tomography (which we call computed tomography angiography) and a newer technique termed magnetic resonance imaging by utilising the reactions of different atomic nuclei to an external magnetic field to provide an image.

Revascularisation is commonly possible by means of thrombolysis, angioplasty or bypass surgery. Dotter introduced the technique of angioplasty in 1964, a procedure whereby a narrow deflated balloon is inserted over a wire into the narrowed artery and inflated to re-widen it. This is done using an angiographic technique, with which you are familiar. Bypasses are performed with either the patient's own vein or a prosthetic alternative. From the 1960s, Thomas Fogarty's embolectomy catheter has improved the results of embolectomy, an operation that still has a fundamental role to play despite the development of newer techniques.

Moreover, not all lower limb amputations need to be above the knee (although this is still a common procedure), with some performed below the knee and some as transmetatarsal procedures. For those with the appropriate inclination and cardiac reserve, prosthetics enable independent mobilisation in many cases. Advancement in imaging has markedly aided judgement of the level of amputation required. Nevertheless, clinical judgement still prevails. In wet gangrene, antibiotics are still necessary. Penicillins are still used but we are a number of generations on.

As you can see, there have been some great advances in the prevention and imaging of occlusive arterial disease in the last 70 years. However, the overall management of established gangrene is little changed. The same basic principles that you describe (of amputation or debridement of the gangrenous tissue) are still standard management today. Plus ça change, plus çest la même chose.

Miss Fiona Myint FRCS Consultant Vascular and General Surgeon 